\title{
Differential drug resistance acquisition to doxorubicin and paclitaxel in breast cancer cells
}

\author{
Feifei $\mathrm{Xu}^{1 \dagger}$, Fengliang Wang $^{2+}$, Ting Yang ${ }^{1}$, Yuan Sheng ${ }^{1}$, Ting Zhong ${ }^{1}$ and Yun Chen ${ }^{1 *}$
}

\begin{abstract}
Background: Several signal transduction pathways have been reported being involved in the acquisition of P-glycoprotein (P-gp) mediated multi-drug resistance (MDR) upon exposure to anti-cancer drugs, whereas there is evidence indicating that the expression and activity of P-gp were not equally or even reversely modulated by different drugs.

Methods: To further illustrate this drug-specific effect, possible mechanisms that enable breast cancer cells MCF-7 to acquire MDR to either paclitaxel (PTX) or doxorubicin (DOX) were investigated in a time-dependent manner.

Results: The results suggested that at least two pathways participated in this process. One was the short and transient activation of NF-kB, the second one was the relatively prolonged induction of PXR. Both PXR and NF-kB pathways took part in the PTX drug resistance acquisition, whereas DOX did not exert a significant effect on the PXR-mediated induction of P-gp. Furthermore, the property of NF-kB activation shared by DOX and PTX was not identical. An attempt made in the present study demonstrated that the acquired resistance to DOX was via or partially via NF-kB activation but not its upstream receptor TLR4, while PTX can induce the drug resistance via TLR4-NF-KB pathway.
\end{abstract}

Conclusions: To our knowledge, this report is among the first to directly compare the time dependence of NF-KB and PXR pathways. The current study provides useful insight into the distinct ability of DOX and PTX to induce P-gp mediated MDR in breast cancer. Different strategies may be required to circumvent MDR in the presence of different anti-cancer drugs.

Keywords: Multi-drug Resistance Acquisition (MDR), P-glycoprotein (P-gp), Drug-specific, Doxorubicin (DOX), Paclitaxel (PTX)

\section{Background}

Chemotherapeutics are an effective treatment against tumors. However, the efficacy of the treatment may be impeded by multi-drug resistance (MDR), a phenomenon that consists in the development of resistance by the tumor [1]. In the case of breast cancer, initially responsive tumors frequently relapse and acquire resistance to a broad spectrum of drugs after the initial sensitivity to cytotoxic agents [2]. Among the recognized mechanisms underlying the MDR, the efflux of the drugs by ATP binding cassette $(\mathrm{ABC})$ transporters in the membrane compartments was the most concerned one [3]. Even though this mechanism has not been unveiled completely, avoiding the appearance of drug resistance and modulating the MDR have been a great challenge to cancer therapy in clinic and laboratory.

\footnotetext{
* Correspondence: ychen@njmu.edu.cn

${ }^{\dagger}$ Equal contributors

'School of Pharmacy, Nanjing Medical University, 818 Tian Yuan East Road, Nanjing 211166, China

Full list of author information is available at the end of the article
}

Among the $\mathrm{ABC}$ transporters, P-glycoprotein (P-gp) is the first described and most extensively studied one [4]. This transporter protein is encoded by the gene multi-drug resistance 1 (MDR1) in human and is expressed widely in epithelial cells of many organs [5]. Its expression can be altered by a variety of xenobiotics, thus affecting its transport activity [6]. As typically and commonly used cytotoxic drugs in the treatment of breast cancer, paclitaxel (PTX, a microtubule-stabilizing drug) and doxorubicin (DOX, a DNA damaging drug) can both enhance the P-gp expression and induce MDR, resulting in the failure of chemotherapy [7]. However, cDNA microarray analysis provided the evidence that isogenic PTX- and DOX-resistant breast cancer cells indicated distinct drug-specific genetic signatures of resistance that accompanied the establishment of PTX or DOX resistance [8]. Differences in the capacity of drugs to induce cross-resistance to each other have been also reported for DOX and PTX [7]. The basis for this drug-specific effect in the process of drug resistance acquisition is so far unclear. Currently, of particular importance 
is to know the extent to which the transporter activity is path-physiologically modulated.

To date, a number of studies have described that activation of nuclear factor-kappa $B(N F-k B)$ leads to the alternation of P-gp activity. However, the results of these studies are inconclusive. Most of them suggested that P-gp was up-regulated by NF- $\mathrm{kB}$ activation $[9,10]$, while others demonstrated a down-regulation effect [11]. In addition to NF- $\mathrm{kB}$, another inducer associated with the $\mathrm{P}$-gp expression and activity is pregnane $\mathrm{X}$ receptor (PXR). As an orphan nuclear receptor known for its activation by structurally diverse compounds, PXR is implicated as a novel regulator of MDR in cancers [12]. Even though a variety of xenobiotics and endogenous ligands have been reported as the activators of PXR and NF-kB $[13,14]$, whether PXR and NF- $k B$ pathways cause the difference of resistance acquisition to DOX and PTX have not been explored yet.

In this study, we investigated the impact of DOX and PTX on the expression and transport activity of P-gp in breast cancer cells MCF-7. The potential modulation of drugs on the NF- $\mathrm{kB}$ and PXR-mediated P-gp induction were evaluated. Since toll-like receptor 4 (TLR4) signaling pathway generally culminates in the activation of NF- $\mathrm{B}$ [15], the role of TLR4 was also investigated. The ultimate aim of this study is to provide further insight into the P-gp mediated MDR acquisition and enhance the efficacy of breast cancer treatment in the presence of different chemotherapy drugs.

\section{Materials and methods \\ Materials and reagents}

PTX was purchased from Hisun Pharmaceutical Co., Ltd. (Zhejiang, China) and DOX was from Sigma-Aldrich (St. Louis, MO, USA). Rhodamine 123 (Rho-123) and Bay 11-7082 were both supplied by Sigma-Aldrich (St. Louis, MO, USA). Triton X-100 and phenylmethanesulfonyl fluoride (PMSF) were from Generay Biotech Co., Ltd. (Shanghai, China). Deoxycholate was from Biosharp (Huaibei, Anhui, China). Penicillin was obtained from CSPC Zhongnuo Pharmaceutical Co., Ltd (Shijiazhuang, China). Streptomycin was obtained from Merro Pharmaceutical Co., Ltd (Dalian, China).

\section{Cell culture and drug treatment}

Human breast cancer cell line MCF-7 was purchased from ATCC (Rockville, MD, USA) and its corresponding DOX-resistant cells (MCF-7/DOX) were obtained from KeyGEN BioTech (Nanjing, China). PTX-resistant cells (MCF-7/PTX) was generously donated by Dr. Sun [16]. MCF-7/DOX cells were cultured in RPMI 1640 media (with L-glutamine and sodium pyruvate) supplemented with $10 \%$ fetal bovine serum (Thermo Scientific Hyclone, Utah, USA) at $37^{\circ} \mathrm{C}$ and $5 \% \mathrm{CO}_{2}$. MCF-7 and
MCF-7/PTX cells were maintained routinely in DMEM media supplemented with $10 \%$ fetal bovine serum, 100 $\mathrm{U} / \mathrm{mL}$ penicillin and $100 \mu \mathrm{g} / \mathrm{mL}$ streptomycin.

\section{Reverse transcriptase (RT)-PCR and real-time quantitative RT-PCR (qRT-PCR)}

Total RNA was isolated from cells using RNAiso Plus reagent (Takara, Dalian, China) according to the manufacture's instructions and quantified using UV absorbance spectroscopy. For single-strand cDNA synthesis, $1 \mu \mathrm{g}$ total RNA was reverse transcribed in a $10 \mu \mathrm{L}$ reaction using the $5 \times$ primescript RT Master Mix (Takara, Dalian, China) at $37^{\circ} \mathrm{C}$ for $15 \mathrm{~min}$. The expression profiles of MDR1 that encodes P-gp in MCF-7, MCF-7/DOX and MCF-7/PTX cells were evaluated using RT-PCR with the MJ Mini Personal Thermal Cycler (Bio-Rad Laboratories, Richmond, USA). Details of primers and predicted band sizes of PCR products are shown in Additional file 1: Table S1. The amplified products were run on 3\% Gel-red (Biotium, CA, USA) stained agarose gel and visualized under UV light.

qRT-PCR for PXR and MDR1 was done using an Applied Biosystems 7500 real-time PCR system (Applied Biosystems, CA, USA). The total reaction volume was $20 \mu \mathrm{L}$ containing $2 \times$ SYBR Green PCR master mix (Takara, Dalian, China), $200 \mathrm{nmol} / \mathrm{L}$ of each primer and $2 \mu \mathrm{L}$ cDNA as template. After two initial steps of $50^{\circ} \mathrm{C}$ for $2 \mathrm{~min}$ and $95^{\circ} \mathrm{C}$ for $6 \mathrm{~min}$, the PCR reaction was run 40 cycles of $95^{\circ} \mathrm{C}$ for $15 \mathrm{~s}$ and $60^{\circ} \mathrm{C}$ for $1 \mathrm{~min}$. Melt cure analyses were done for all samples and only sharp melting points were observed, indicating a specific signal and no primer dimmers or mispriming. The $\mathrm{Ct}$ value is defined as the fractional cycle number at which the fluorescence passes the fixed threshold. Quantification of PXR and MDR1 mRNA for each sample was calculated by correcting for against the $\mathrm{Ct}$ level of GAPDH. The data are normalized to controls (untreated cells) and presented as mean data ( \pm S.D.) of three different experiments.

\section{Measurement of P-gp activity in MCF-7 Cells}

P-gp activity in MCF-7 cells was assessed based on Rho123 uptake. Rho-123 is a typical substrate of P-gp, and a decrease or increase in Rho-123 uptake by cells reflects the enhancement or suppression of P-gp function, respectively. Briefly, cells were seeded onto 6-well plates and pretreated with drugs, then incubated with $2.5 \mu \mathrm{M}$ Rho- 123 in the dark at $37^{\circ} \mathrm{C}$ for $60 \mathrm{~min}$. After washed twice with ice-cold PBS, cells were harvested in $400 \mu \mathrm{L}$ of $1 \%(\mathrm{v} / \mathrm{v})$ Triton X-100 in PBS. Then, the whole cell lysate was centrifuged at $13,000 \mathrm{rpm}$ for $10 \mathrm{~min}$ at $4^{\circ} \mathrm{C}$. The amount of Rho-123 was determined using the 96-well fluorescence plate reader with excitation/emission wavelengths at 510/536 nm using EnSpire 2300 (PerkinElmer, Waltham, MA, USA). The total protein concentration was 
measured by the BCA protein assay kit (Pierce, Rockford, USA) according to the manufacturer's protocol. The amount of intracellular Rho-123 was normalized to the total protein concentration. The ratio of these data in the absence or presence of drugs/inhibitors is indicative for the activity of P-gp. The data are presented as mean data ( \pm S.D.) of three different experiments. In this study, the initially selected concentrations of PTX were $1,2.5,5,10,25,50 \mathrm{nM}$ and those of DOX were 10, 25, 50, 100, 250, $500 \mathrm{nM}$. Then, the cells were pretreated with PTX and DOX at the concentrations having the maximal effect.

\section{Protein extraction and Western blotting}

The cells were washed twice with ice-cold PBS and lysed in RIPA lysis buffer (Beyotime, Shanghai, China). After incubated on ice for $40 \mathrm{~min}$, the whole cell lysate was centrifuged at 12,000 rpm to remove cellular debris. Cytosolic and nuclear proteins were isolated using the NE-PER nuclear and cytoplasmic extraction kit (Pierce, Rockford, USA) according to the manufacturer's protocol. $50 \mu \mathrm{g}$ of total protein was resolved by 4-12\% SDS-PAGE, unless stated otherwise, and transferred onto a polyvinylidenefluoride (PVDF) membrane (Millipore, Billerica, MA, USA). Western blot analysis was performed using primary antibodies for PXR (1:1000, Biolegend, CA, USA), NF- $\mathrm{kB}$ p65 (1:500, Cell signaling, Beverly, MA, USA), P-gp (1:200, Abcam, Cambridge, UK) GAPDH, Actin (1:2000, Bioworld, Nanjing, China) and Anti-TATA binding protein (TBP) antibody (1:500, Proteintech, Chicago, IL, USA), followed by HRP-conjugated goat anti-mouse/rabbit IgG (1:5000, MultiSciences Biotech. Co., Ltd., Hangzhou, China). The proteins were then detected using enhanced chemiluminescence reagent (Pierce, Rockford, USA) according to the manufacturer's protocol.

\section{Analysis of NF-KB p65 translocation using confocal microscopy}

MCF-7 cells were grown on confocal petri dish and treated with two drugs for $24 \mathrm{~h}$. Then, the cells were washed with PBS, fixed with $4 \%$ paraformaldehyde and permeabilized with PBST ( $0.2 \%$ Triton X-100 in PBS) solution for the entrance of NF-kB p65 antibody. The cells were blocked with $5 \%$ BSA in PBS, followed by the rabbit monoclonal NF- $\kappa B$ p65 antibody (1:25, Cell signaling, Beverly, USA) prepared in 3\% BSA in PBS overnight. After washing three times with PBS, Dylight 488 Affinipure goat anti-rabbit IgG $(\mathrm{H}+\mathrm{L})(1: 200$, EarthOx, California, USA) secondary antibody was added and incubated at room temperature for $1 \mathrm{~h}$. Then DAPI stain $(10 \mu \mathrm{g} / \mathrm{ml})$ for nuclei was added and images were acquired at room temperature using a LSM700 confocal microscope with a C-Apo $\times 40$ water immersion lens (Carl Zeiss, Germany).

\section{Cellular modulation of PXR expression with small interfering RNA (siRNA)}

The siRNA sequence targeting human PXR gene and the negative control that consisted of a non-complementary sequence were developed by GenePharma (Shanghai, China). Three different sequences were evaluated first. The PXR siRNA with the following sense and anti-sense sequences was chosen: 5'-GAUGGACGCUCAGAUGAA ATT-3' (sense) and 5'-UUUCAUCUGAGCGUC- CAUC TT-3' (anti-sense). Cells were grown to approximately $80 \%$ confluence in 6-well plates and transfected with 20 pM PXR siRNA using Lipofectamine 2000 (Invitrogen, Breda, Netherlands). The cells were incubated at $37^{\circ} \mathrm{C}$ with $5 \% \mathrm{CO}_{2}$ for subsequent analysis.

\section{Inhibition of TLR4 and NF-KB pathways}

BAY 11-7082, which can block the phosphorylation of $\mathrm{I} \kappa \mathrm{B}$ and decrease the expression of adhesion molecules, was used as an NF- $\mathrm{kB}$ inhibitor [17]. MCF-7 cells were first grown in 6-well plates and incubated for $48 \mathrm{~h}$, prior to the incubation with $5 \mu \mathrm{M}$ BAY $11-7082$ for $2 \mathrm{~h}$, followed by PTX and DOX treatment. To measure the function of TLR4, which is the upstream signal transduction of NF- $\mathrm{kB}$ activation, TLR4 was blocked by a pretreatment with $2 \mu \mathrm{g}$ of the anti-human TLR4-blocking antibody (Hycult Biotech, Holland).

\section{Data analysis}

Mann-Whitney test was used to analyze the difference between two groups. Data were presented as mean \pm S.D. The general acceptance level of significance was $\mathrm{p}<0.05$.

\section{Results}

\section{P-gp and MDR1 mRNA expression in cells}

Three MCF-7 cell lines were first phenotyped for P-gp expression using Western blotting. Consistent with previous studies [18,19], a well-defined band at approximately $170 \mathrm{kDa}$ was detectable in MCF-7/DOX and MCF-7/PTX cells compared to their parental MCF-7 cells (Figure $1 \mathrm{~A}$ and $\mathrm{B}$ ). In addition, mRNA expression of Pgp was determined. As expected, similar result was obtained. MCF-7 cells expressed a low level of MDR1 mRNA, barely detectable using RT-PCR assay (Figure 1C). Up-regulation of MDR1 mRNA was observed in drugresistant cells. Notably, the observed differences between Western blotting and RT-PCR results were consistent with the previous studies that the concordance between gene and protein expression findings usually ranged from poor to moderate [20]. Interestingly, both approaches indicated a difference in the increase of P-gp level between MCF-7/ DOX and MCF-7/PTX cells. The enhancement of P-gp in MCF-7/DOX cells was $\sim 1.7$ fold greater than that in MCF-7/PTX cells. 


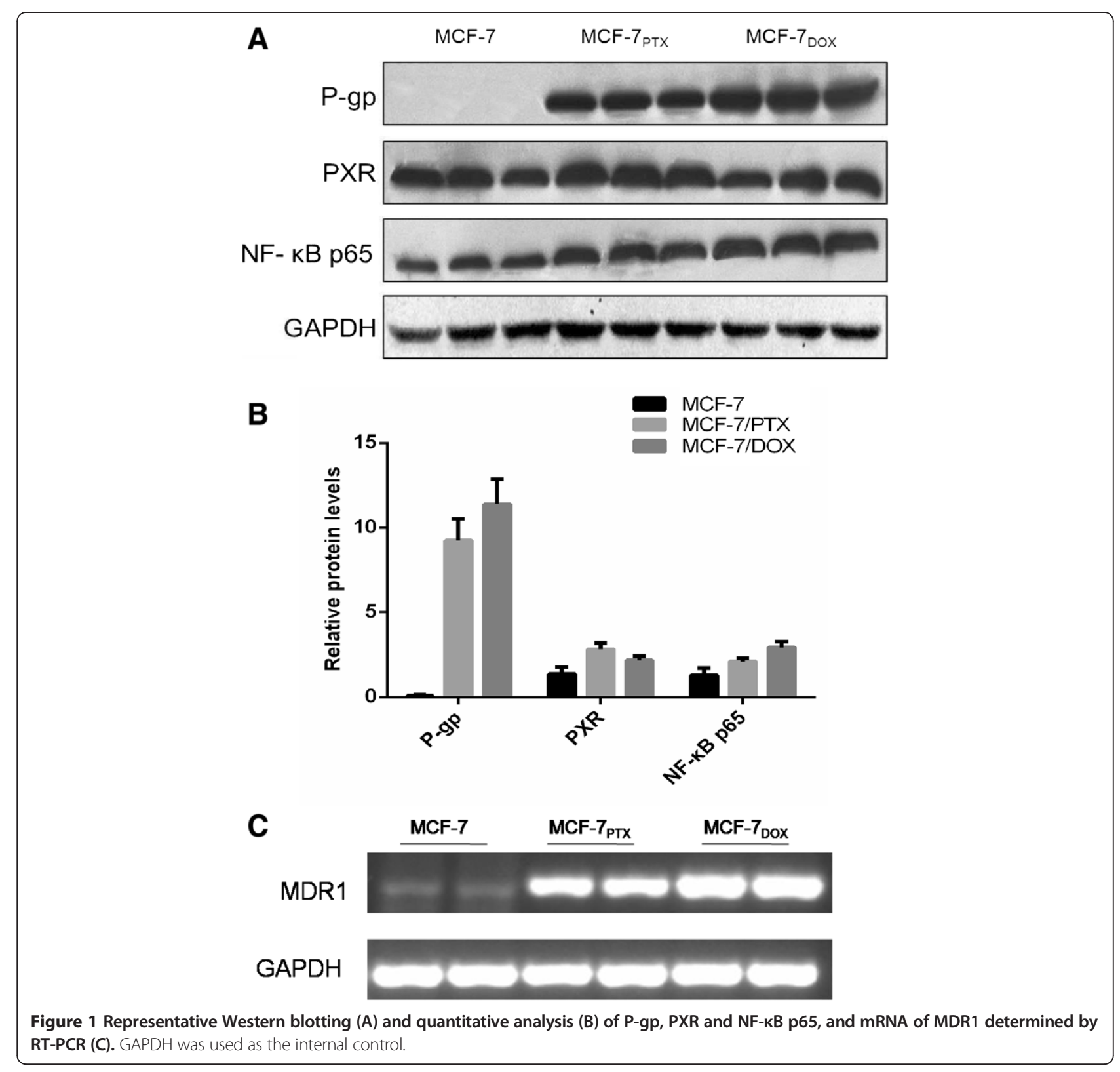

\section{PXR and NF-KB expression in cells}

Both PXR and NF- $\mathrm{kB}$ are highly likely responsible for the modulation of P-gp expression and activity. Thus, the expression PXR and NF-kB p65 in MCF-7/PTX and MCF-7/DOX cells were first conducted. Since activation of NF- $\mathrm{KB}$ is associated with nuclear translocation of the p65 component of the complex, quantification of nuclear p65 can be used as a parameter for NF- $\mathrm{kB}$ activation [21]. As shown in Figure 1A, MCF-7/DOX cells have a higher enhancement of NF- $\mathrm{kB} / \mathrm{p} 65$, even though an increase was obtained in both MCF-7/DOX and MCF-7/PTX cells. On the other hand, MCF-7/PTX cells have a $\sim 1.3$-fold higher expression of PXR than its parental MCF-7 cells, whereas the difference of this receptor between MCF-7/DOX and MCF-7 cells was not easily distinguishable.

\section{Impact of DOX and PTX on P-gp expression and activity} in short-term and long-term

To closely monitor the PXR and NF- $\mathrm{BB}$ changes in the development of resistance to DOX and PTX, MCF-7 cells were induced by these drugs in a time course here. The first step in the experimental design is the selection of DOX and PTX concentration for the treatment of cells. Thus, an investigation was performed to evaluate the P-gp expression of MCF-7 cells as function of PTX 


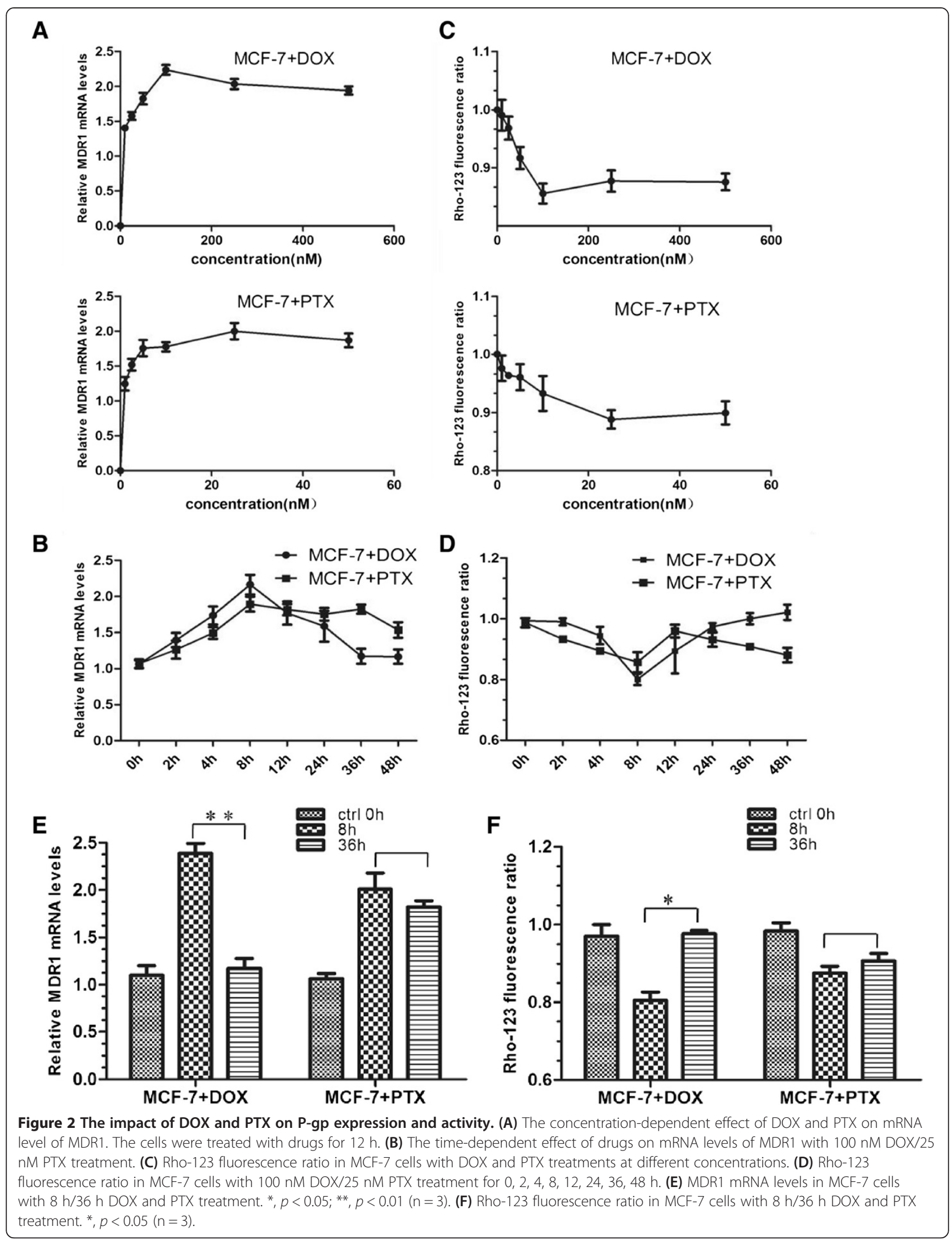


and DOX concentrations, respectively. The selected concentrations of PTX were $1,2.5,5,10,25,50 \mathrm{nM}$ and those of DOX were 10, 25, 50, 100, 250, $500 \mathrm{nM}$, following their previously reported $\mathrm{IC}_{50}$ values [7]. The results suggested that the maximal effect of drugs were observed at DOX $100 \mathrm{nM}$ and PTX $25 \mathrm{nM}$ (Figure 2A and $\mathrm{C}$ ) with $12 \mathrm{~h}$ treatment time. Therefore, these concentrations were used in the following experiments.

The cells were subsequently analyzed for mRNA levels of MDR1 after different drug treatment lengths. As a result, P-gp induction was an early event in the process of drug resistance acquisition (Figure 2B). After a comparison at individual time points, we found that the increase in the level of MDR1 mRNA after exposure to DOX and PTX reached 2.39 and 2.01 folds at $8 \mathrm{~h}$, suggesting a transcriptional regulation of P-gp by these drugs (Figure 2E). A higher enhancement was achieved by DOX. However, this up-regulation was down-regulated following a more prolonged exposure (e.g., $36 \mathrm{~h}$ ) to PTX (1.82 fold), whereas this alternation was not observed for DOX (1.17 fold, $\mathrm{P}>0.05$ ) (Figure 2E).

Meanwhile, P-gp transport activity was also analyzed. We exposed the cells to the fluorescent P-gp substrate Rho-123 and measured P-gp activity by comparing the intracellular accumulation of Rho-123 [22,23]. The concentration and time points were the same as those used in the qRT-PCR assay (Figure 2C-D). In agreement with protein level, intracellular Rho-123 significantly decreased in $8 \mathrm{~h}$ after drug exposure $(80.1 \%$ for DOX and $87.5 \%$ for PTX), indicative of a declined P-gp function (Figure 2F). In a long-term exposure, a similar phenomenon to the mRNA result was also observed that the function of P-gp was resumed in DOX not PTX treated cells.

\section{Activation of NF-KB pathway}

$\mathrm{NF}-\mathrm{kB}$ is a transcription factor that induces the expression of genes involved in many biological responses including inflammation, cell proliferation and survival [24]. The majority of NF- $\mathrm{kB}$ exists as a heterodimer of p65/p50 proteins sequestered in the cytosol and bound to inhibitory $I_{\kappa} B$ proteins [25]. Stimulation of cells can activate I $\mathrm{KB}$ kinases that phosphorylate $I \kappa B$ and result in ubiquitination and proteosomal degradation of IкB. Then the free p65/p50 complex enters the nucleus and initiates transcription of downstream effector genes [24]. Thus, the appearance of p65 in the nuclear extracts of cells can be a sign of NF-kB activation.

In terms of p65 translocation, Western blotting of cytoplasmic and nuclear p65 was performed. Actin and TBP were used as the loading control of cytoplasmic and nuclear fractions, respectively. As a result, both DOX and PTX enhanced the level of p65 in the nuclear region. Time-dependent analysis of NF- $\mathrm{B}$ translocation from 0 to $8 \mathrm{~h}$ indicated a rapid translocation rate maximizing at $2 \mathrm{~h}$ (Figure 3A-B). In addition, a higher value was achieved upon exposure to DOX than PTX (Figure 3C-D). Of note, an apparent decline of p65 at time points longer than $2 \mathrm{~h}$ after the treatment of PTX was observed, probably attributed to the restored nuclear export of p65.

\section{Inhibition of NF-KB pathway}

To further investigate the NF-kB pathway, we examined the effect of Bay 11-7082 on P-gp expression and activity. Bay $11-7082$ is an inhibitor of IKB $\alpha$ phosphorylation, thereby permitting $\mathrm{I} \kappa \mathrm{B} \alpha$ to bind and inactivate NF- $\mathrm{kB}$ [17]. As shown in Figure 4A-B, both DOX and PTX displayed significantly lower entry of nuclear p65 in the presence of Bay 11-7082 at $2 \mathrm{~h}$. The reduced mRNA expression and activity of P-gp were also observed (Figure 4C-D). In addition, P-gp returned to its baseline in DOX treated cells, whereas it only partially recovered in PTX treated cells and the P-gp induction was not completely abolished. Furthermore, inhibition of NF- $\mathrm{kB}$ by Bay $11-7082$ at $36 \mathrm{~h}$ was not significant for both DOX and PTX treatments. Nevertheless, the resumed value at $36 \mathrm{~h}$ with the incubation of PTX was even greater than that at $8 \mathrm{~h}$ and of control, whereas DOX did not show such a trend, implying that at least another factor in addition to NF- $\mathrm{kB}$ participated in the P-gp modulation in PTX treated cells.

\section{NF-KB activation via TLR4}

In the upstream signal transduction of NF- $\mathrm{kB}$ activation, several signaling molecules can bind to their corresponding receptors, leading to the NF- $\mathrm{KB}$ signaling cascade [26]. Among them, TLRs generally signal through a MyD88dependent manner, which involves the early activation of NF- $k B$ [27]. As the first TLR discovered in humans, together with that both DOX and PTX have been reported as its potential ligands $[28,29]$, TLR4 was examined in this study. The involvement of TLR4 was investigated using blocking antibody. The result indicated that PTX-induced NF- $\kappa \mathrm{B}$ activation and P-gp overexpression were inhibited by anti-TLR4 antibody (Figure 5A-C). On the contrary, there was no significant alternation in P-gp level of DOX treated cells.

Finally, NF-kB pathway was also examined using confocal microscopy (Figure 6). The effects of anti-TLR4 antibody and Bay 11-7082 were demonstrated with Dylight 488 (green fluorescence) and DAPI (blue fluorescence) as p65 and nuclear stains. The obtained results were consistent with those of Western blotting. These data provided alternative evidence of NF- $\mathrm{BB}$ pathway underlying the drug resistance acquisition.

\section{Activation of PXR pathway}

Time-course study of PXR induction indicated that the expression of PXR mRNA increased with the treatment 


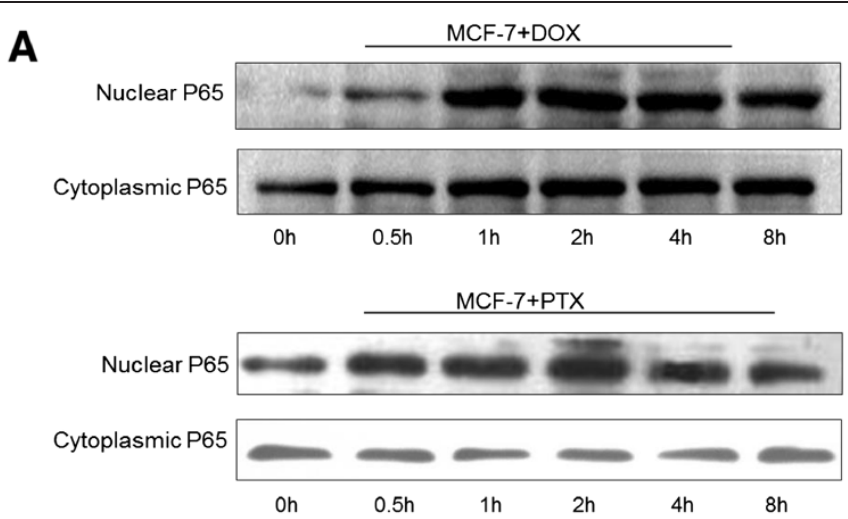

B
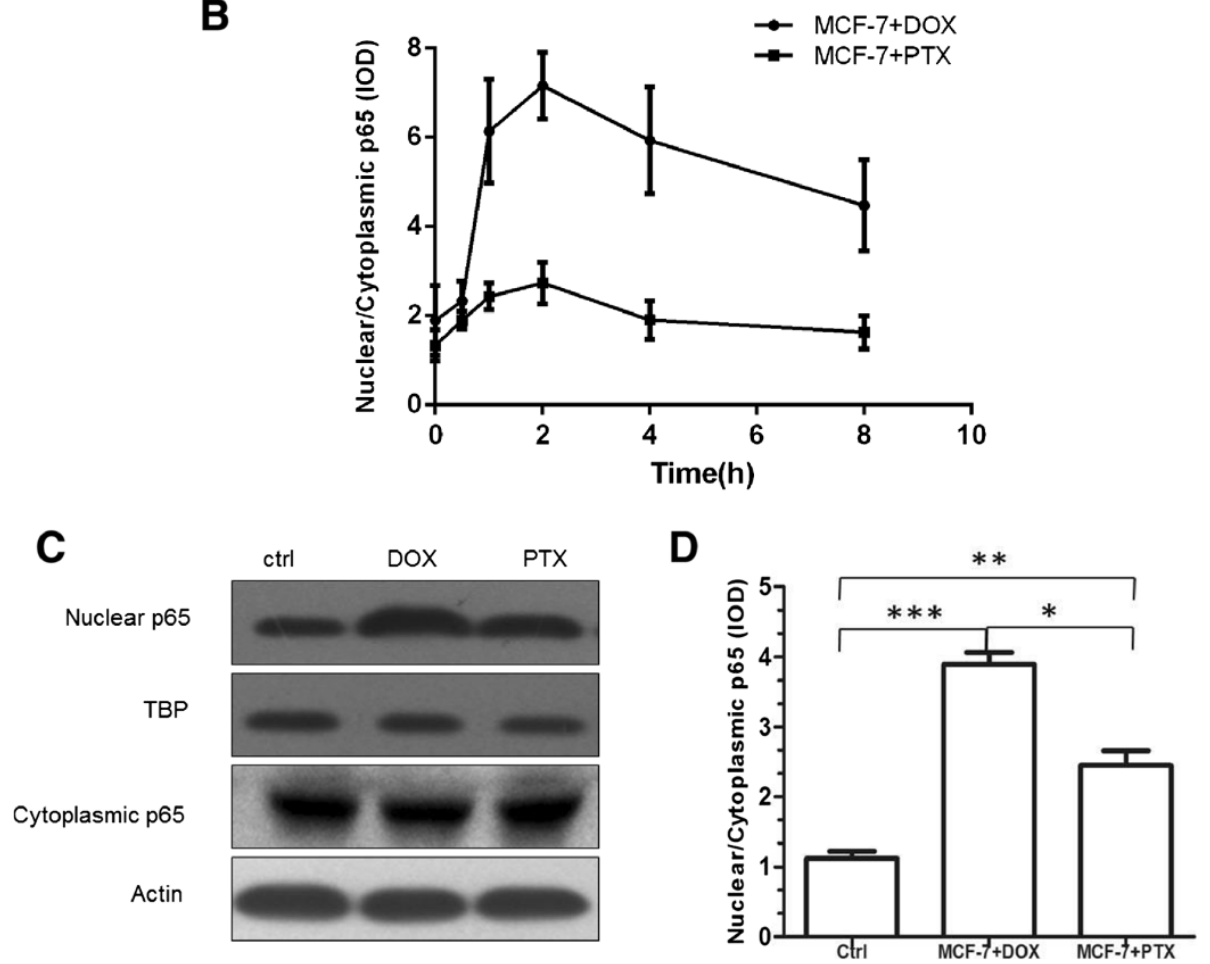

Figure 3 p65 translocation in MCF-7 cells after the treatment of DOX and PTX. (A) Western blotting and (B) nuclear:cytoplasmic ratio of NF-KB p65 in cytoplasmic and nuclear fractions of DOX and PTX treated MCF-7 cells at 0, 0.5, 1, 2, 4, 8 h. (C) Western blotting of NF-kB p65 after $2 \mathrm{~h}$ treatment of DOX and PTX using Actin and TBP as loading controls. (D) A quantitative analysis of nuclear:cytoplasmic ratio of p65 in (C). ${ }^{*}, p$ $<0.05 ;{ }^{* *}, p<0.01 ;{ }^{* * *}, p<0.001(n=3)$.

of PTX in the first $24 \mathrm{~h}(\mathrm{p}<0.05)$, and then kept on a plateau over $24 \mathrm{~h}$ later (Figure 7A). Correspondingly, PXR protein level enhanced in accordance with the observed level of mRNA (Figure 7B). On the contrary to PTX, DOX can not cause PXR change at both protein and mRNA levels.

To further examine whether the induction of DOX and PTX on P-gp was via the PXR activation, we designed a small interfering RNA targeting PXR to knockdown its expression. As a result, silencing efficiency of $80 \%$ was achieved compared with that of the nontargeting siRNA (Figure 7C). Neither mock (absence of
siRNA) nor non-targeting siRNA had any effect on PXR mRNA levels. Then these silenced cells were used for PTX and DOX treatment and the result is shown in Figure 7D. While control cells (mock) exhibited an extent of P-gp induction by PTX, the siRNA-mediated PXR knock-down cells have an alleviated increase of Pgp in both expression and activity at $36 \mathrm{~h}(\mathrm{p}<0.01)$, strongly suggesting that this nuclear receptor was indeed implicated in the regulation of MDR1 gene. In contrast to PTX, DOX did not show such a result. There was no significant difference $(p>0.05)$ between the mock and siRNA transfected cells. Most importantly, relatively 


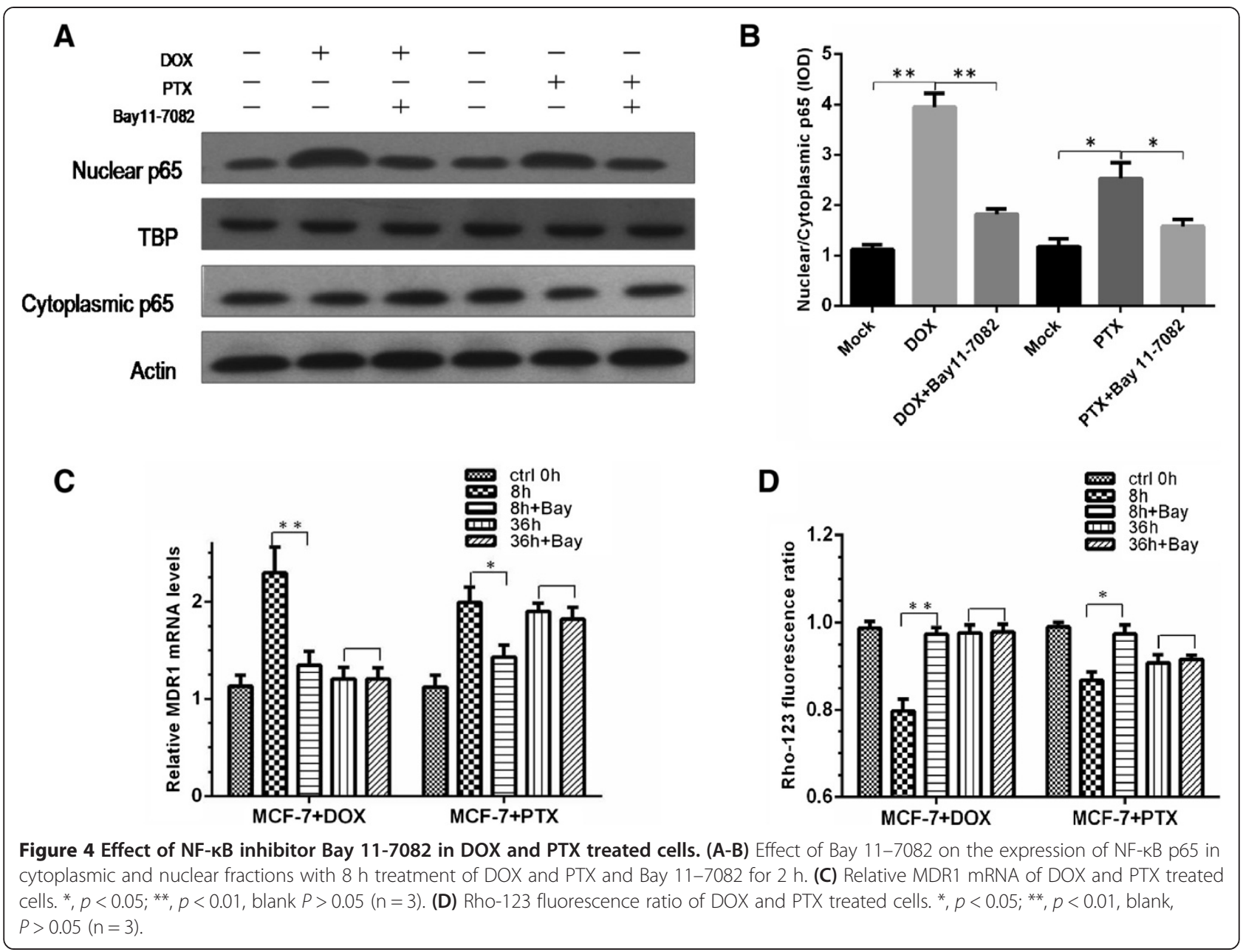

long-term activation of PXR was observed. To be specific, siRNA transfected cells had a significant decline of P-gp level at $36 \mathrm{~h}$, but not at $8 \mathrm{~h}$.

\section{Discussion}

As earlier mentioned, DOX and PTX are used to treat breast cancer via distinct mechanisms [30]. The mechanism of DOX action is topoisomerase II inhibition and free radical generation. On the other hand, the effect of paclitaxel is related to its ability to bind to tubulin, to promote microtubule assembly, and to stabilize microtubules by bundle formation. In addition to this difference, there are several studies indicating that their ability to induce drug resistance is agent-specific $[7,8]$. However, few investigations provide significant insight into possible signal transduction pathways that enable breast cancer cells to acquire resistance to either PTX or DOX. In this study, MDR1 mRNA and Rho123 assay were used to monitor the expression and activity of P-gp. The time-dependent result indicated that drug resistance induced upon exposure to PTX reserved after reaching the peak value, different from an apparent decline observed in DOX treated cells. This difference may be attributed to distinct ability of DOX and PTX to induce P-gp expression. It is reasonable to assume that multiple at least two pathways participated in the modulation of P-gp expression and function. One is short-term; the second one is relatively long-term.

There are several possible mechanisms underlying P-gp modulation disclosed over the past several years [31,32]. Among them, one potential intracellular target is NF- $\mathrm{kB}$. As reported previously, both PTX and DOX shared the property of NF-kB activation [30]. Since transcription of I $\mathrm{B} \alpha$ is positively autoregulated by NF- $\kappa \mathrm{B}$, activation of $\mathrm{NF}-\mathrm{kB}$ is usually self-terminated within minutes to hours, appearing short and transient $[33,34]$. In this study, the appearance of p65 at early time points (i.e., $2 \mathrm{~h}$ ) and the incompetence of NF- $\mathrm{kB}$ inhibitor at a late time point (i.e., $36 \mathrm{~h}$ ) were consistent with its rapid nature in in vitro studies [34]. Furthermore, the partially restored level of P-gp at $8 \mathrm{~h}$ and its enhanced level at $36 \mathrm{~h}$ in PTX treated cells in the presence of NF- $\mathrm{kB}$ inhibitor confirmed that the impact of NF-kB pathway was less significant on the 


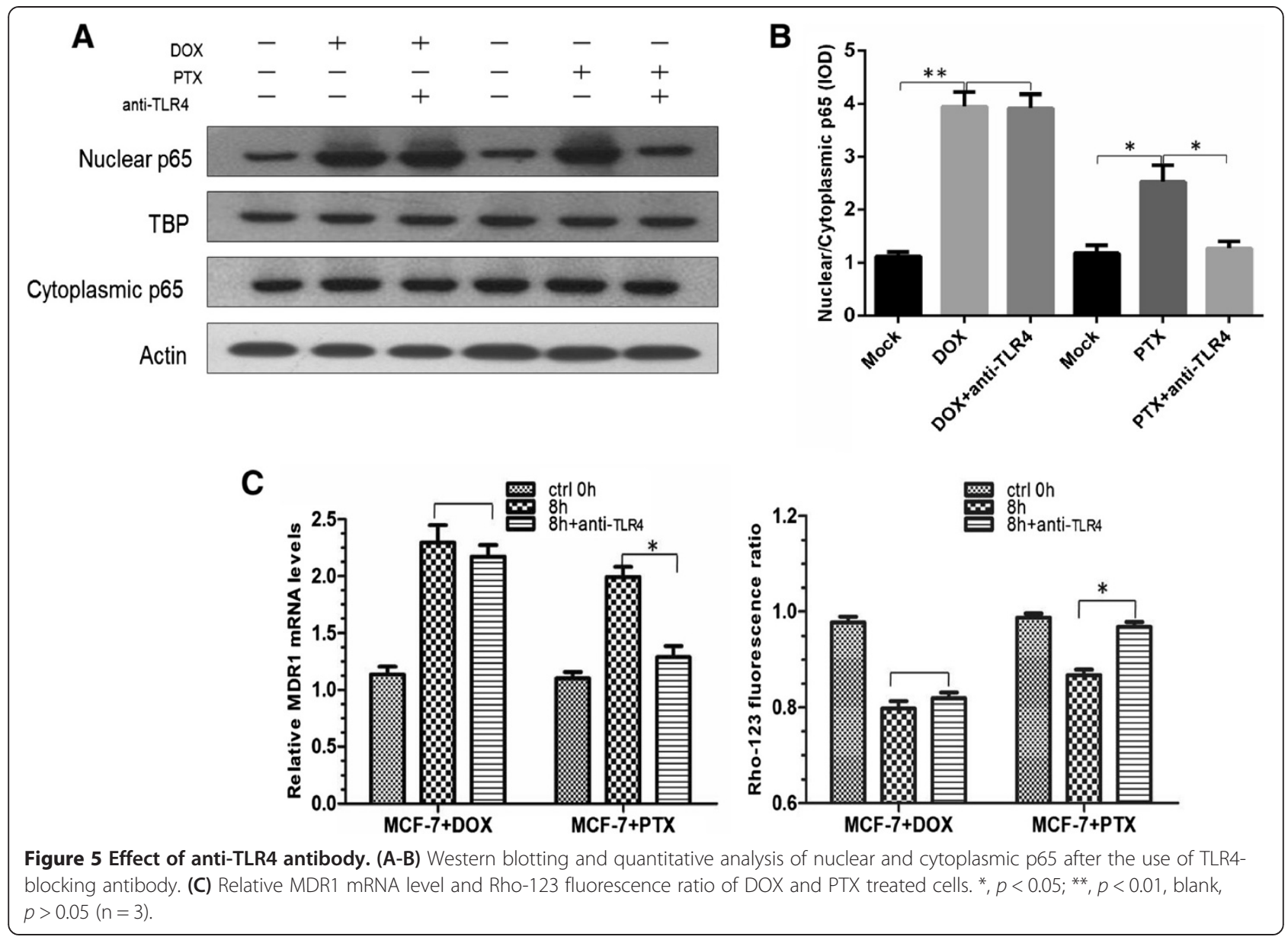

resistance acquisition to PTX, and provided evidence that at least one more pathway took part in the PTX drug resistance acquisition than that of DOX.

PXR has been identified as another major regulator of P-gp induction $[12,35]$. Of the 170 xenobiotics tested, $54 \%$ of them demonstrated some level of PXR transactivation [13]. PTX was one of them. Different from PTX, DOX did not exert a significant effect on both PXR activation and the PXR-mediated induction of proteins, for example P450 3A4 (CYP3A4) [36]. Our results were in agreement with these findings, indicating that PTX but not DOX activated PXR-mediated P-gp induction and affected the expression and activity of P-gp. Compared to short-term activation of NF- $\mathrm{kB}$ signaling, the activation of PXR on P-gp seemed relatively long-term. The induction of PXR culminated at the time points (i.e., $24 \mathrm{~h}$ ) longer than that of NF-kB and was then persistent at a stable level in our experimental period (i.e., 24-36 h). Similarly, the protein level of P-gp in PXR siRNA-transfected cells was more influenced at late time points with the treatment of PTX. Although this chronic effect has been previously reported in vivo $[37,38]$, the direct comparison of the time dependence of NF- $\mathrm{kB}$ and
PXR activation was firstly performed in this study. Notably, the combined data of these two pathways greatly matched the alternation trend of $\mathrm{P}$-gp at protein and mRNA levels.

Despite of NF- $\mathrm{kB}$ and PXR signaling pathways investigated here, several issues observed in the experiments remained inclusive. For example, P-gp level was not equally induced by DOX and PTX via NF- $\mathrm{BB}$ activation. DOX treated cells obtained a higher P-gp expression and activity, which may lead to the ultimate higher P-gp level in MCF-7/DOX cultured cells. Unfortunately, the precise mechanisms that allow drugs to induce NF- $\mathrm{kB}$ activation have not been fully illustrated [39]. Since both DOX and PTX are potential ligands of TLR4 in the upstream signal transduction of NF- $\mathrm{kB}$, we hypothesized here that TLR4 may be involved in the up-regulation of $\mathrm{P}$-gp expression via NF-kB. The results indicated that there was a possibility that the acquired resistance to DOX was via or partially via NF-kB activation but not TLR4. PTX can induce the drug resistance via TLR4NF-kB pathway.

It deserves to mention that TLR4 is not the single receptor upstream the NF-kB pathway. It was selected here 

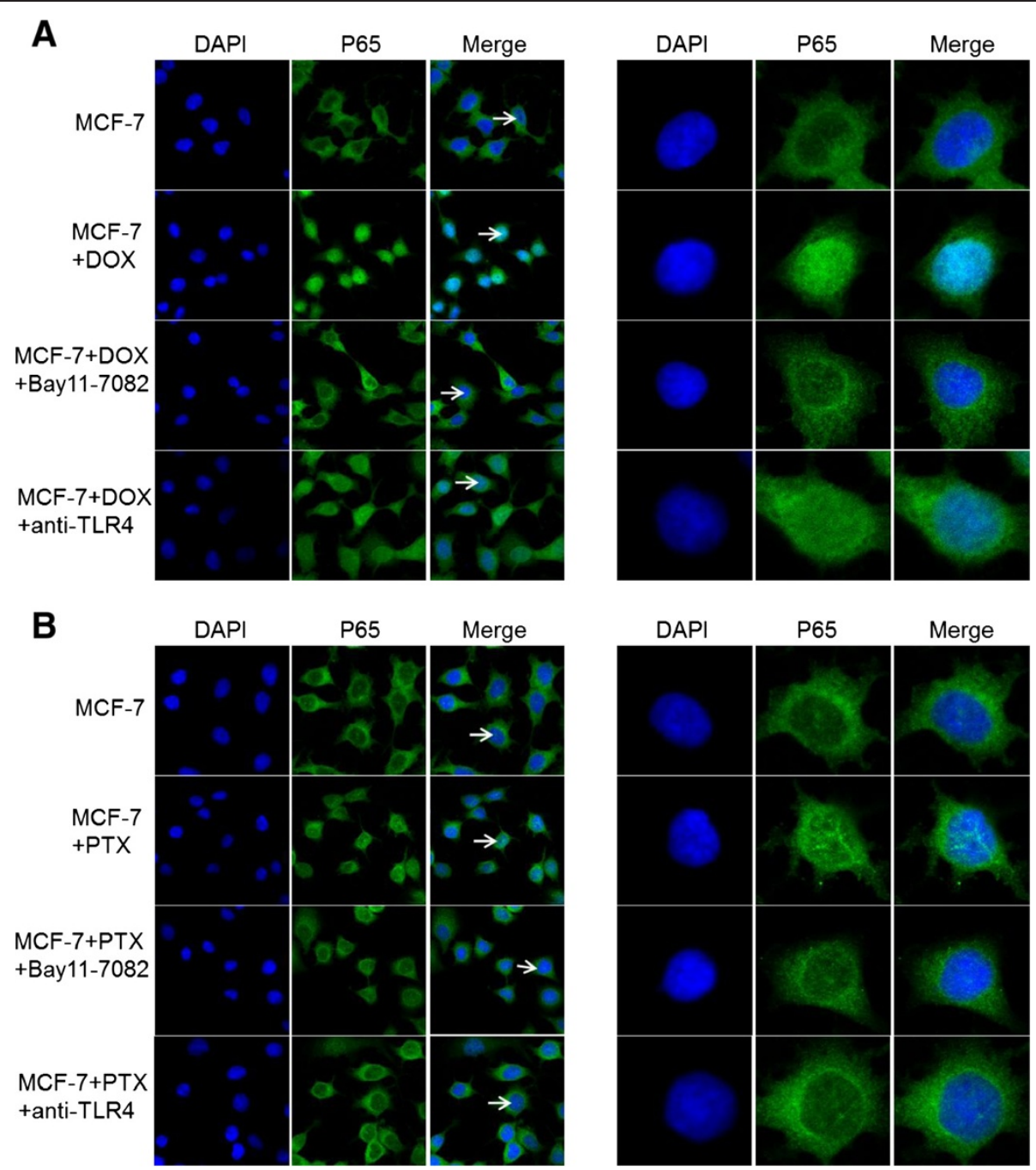

Figure 6 Confocal images of p65 in cells after the treatment of DOX (A) and PTX (B) with or without Bay 11-7082 inhibition and TLR4 antibody blocking. Cells were stained with Dylight 488 (green fluorescence) for p65 and co-stained with DAPI (blue) for positive identification of nuclei. The cells (arrow) are also enlarged at single-cell level for clarification (right images).

largely due to it being as the most potential target of DOX and PTX. In addition to TLR4, NF- $\mathrm{kB}$ can also be activated by other receptors, such as IL-1R, TNF-R and other TLRs [26]. These upstream signaling components are also receptor-specific. Furthermore, the target gene products of NF- $\mathrm{KB}$ include many cytokines, chemokines and cell adhesion molecules [13]. Previous studies have shown that these products can be inducers of P-gp under several pathological conditions, such as infection, tumor, and diabetes mellitus [14-16]. For instance, DOX can inhibit the transcriptional activation of the oxidative stress-responsive heat shock factor 1 (HSF-1) and the subsequence declined expression of heat shock proteins in turn reverse the drug resistance by inhibiting MDR1/P-gp expression [40]. Such findings may be employed to explain drug resistance acquired upon exposure to DOX. Therefore, further studies will be required to address these issues.

Finally, we like to point out that the association between NF- $\mathrm{kB}$ and PXR signaling pathways was not explored in this study. In fact, recent studies revealed that a possible functional link may exist between them [41]. For instance, NF- $\mathrm{kB} / \mathrm{p} 65$ can disrupt the connection of the PXR-RXR $\alpha$ complex with DNA sequences [42]. On the other hand, activated PXR was able to reduce the activity of NF-kB [43]. Thus, their mutual inhibitory potential deserves further assessment in the future.

Therefore, this study illustrated the differential drug resistance acquisition to DOX and PTX in MCF-7 cells by exploring NF- $\mathrm{kB}$ and PXR pathways. Recognition of this difference could help us to provide better treatment 


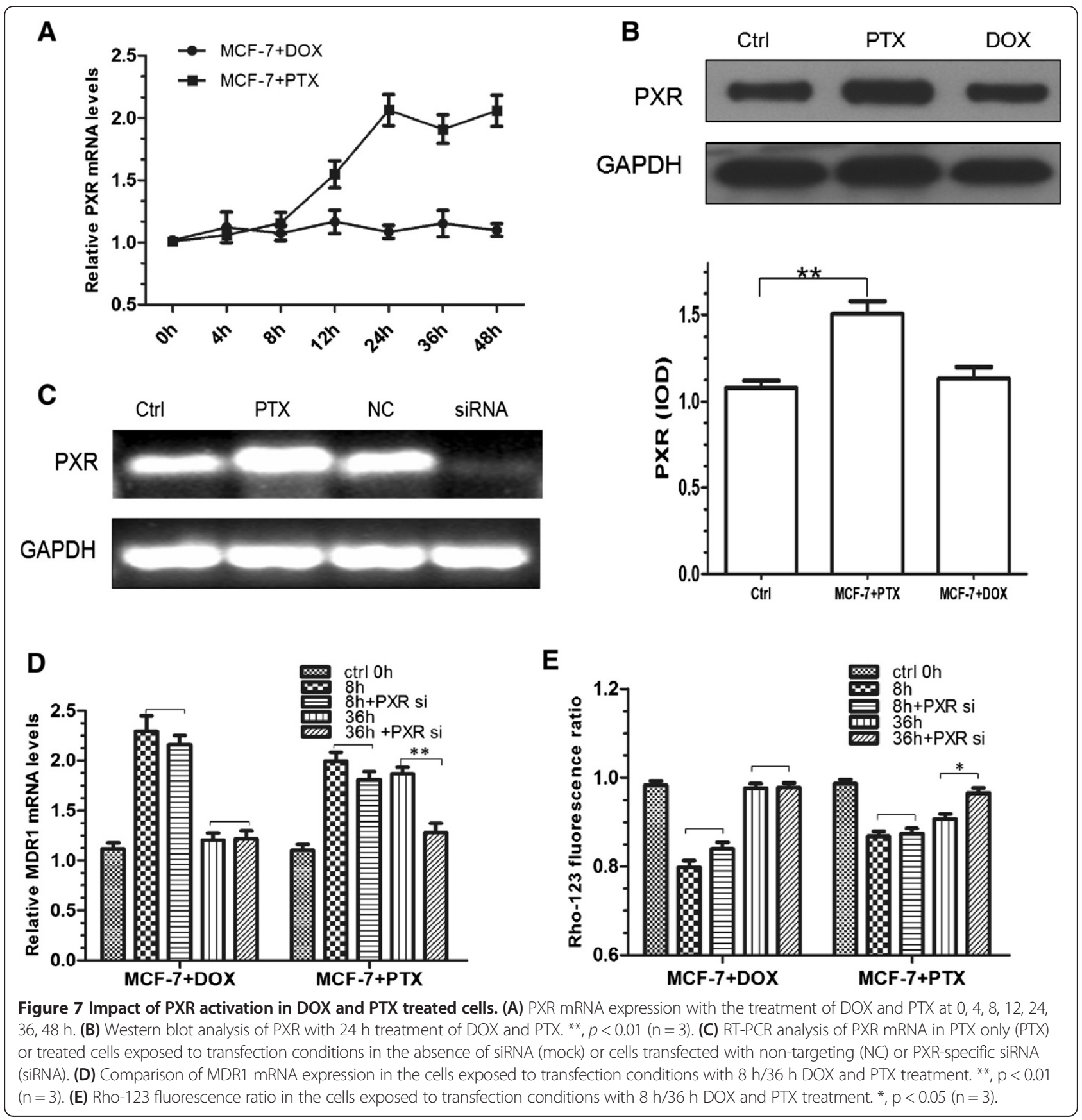

strategy in clinical practice. In the presence of other potential signaling components and interactions, more investigation is in demand.

\section{Conclusions}

To our knowledge, this report is among the first to directly compare the time dependence of NF- $\mathrm{kB}$ and PXR pathways. Differential drug resistance acquisition to DOX and PTX in breast cancer MCF-7 cells was depicted. As a short-term activation, NF- $\mathrm{B}$ participated in both DOX and PTX induction of P-gp. On the contrary, PXR pathway is a relatively prolonged activation and only PTX has an effect on the PXR-mediated induction of P-gp. This study provides significant insight into the possible pathways through which resistance to agents may be acquired in breast cancer. However, it deserves to point out that a wide variety of signaling pathways are involved in P-gp mediated MDR in addition to NF- $\mathrm{kB}$ and PXR, including mitogen-activated protein kinase (MAPK), c-Jun $\mathrm{NH}_{2}$-terminal kinase (JNK), p38, cyclic adenosine monophosphate-dependent protein kinase, phosphatidylinositol 3-kinase and protein kinase $\mathrm{C}$ 
[44]. Additional studies about these pathways will be required to better understand the drug acquisition process and provide strategies to circumvent MDR.

\section{Additional file}

Additional file 1: Table S1. Sequences of Primers used for RT and Real-time PCR Analysis.

\section{Competing interests}

The authors declare that they have no competing interests.

\section{Authors' contributions}

FX, FW and YC participated in the research design. FX, TY and TZ conducted the experiments. YS performed the data analysis. YC drafted the manuscript. All authors read and approved the final manuscript.

\section{Acknowledgements}

The National Natural Science Fund (21175071), the Project sponsored by SRF for ROCS, SEM (39), the Jiangsu Six-type Top Talents Program (D) and the Open Foundation of Nanjing University (SKLACLS1102) awarded to Dr. Chen are gratefully acknowledged. The authors would also like to thank American Journal Experts for proofreading the article.

\section{Author details}

${ }^{1}$ School of Pharmacy, Nanjing Medical University, 818 Tian Yuan East Road, Nanjing 211166, China. ${ }^{2}$ Nanjing Maternity and Child Health Care Hospital, Nanjing 210004, China.

Received: 7 May 2014 Accepted: 4 December 2014

Published online: 21 December 2014

\section{References}

1. Altan N, Chen Y, Schindler M, Simon SM: Defective acidification in human breast tumor cells and implications for chemotherapy. J Exp Med 1998 187(10):1583-1598

2. Faneyte IF, Kristel PM, van de Vijver MJ: Determining MDR1/P-glycoprotein expression in breast cancer. Int J Cancer 2001, 93(1):114-122.

3. Glavinas H, Krajcsi P, Cserepes J, Sarkadi B: The role of ABC transporters in drug resistance, metabolism and toxicity. Curr Drug Deliv 2004, 1(1):27-42.

4. Juliano $R L$, Ling $V$ : A surface glycoprotein modulating drug permeability in Chinese hamster ovary cell mutants. Biochim Biophys Acta 1976, 455(1):152-162.

5. Gottesman MM, Pastan I: Biochemistry of multidrug resistance mediated by the multidrug transporter. Annu Rev Biochem 1993, 62:385-427.

6. Bain LJ, McLachlan JB, LeBlanc GA: Structure-activity relationships for xenobiotic transport substrates and inhibitory ligands of P-glycoprotein Environ Health Perspect 1997, 105(8):812-818.

7. Guo B, Villeneuve DJ, Hembruff SL, Kirwan AF, Blais DE, Bonin M, Parissenti AM: Cross-resistance studies of isogenic drug-resistant breast tumor cell lines support recent clinical evidence suggesting that sensitivity to paclitaxel may be strongly compromised by prior doxorubicin exposure. Breast Cancer Res Treat 2004, 85(1):31-51.

8. Villeneuve DJ, Hembruff SL, Veitch Z, Cecchetto M, Dew WA, Parissenti AM: cDNA microarray analysis of isogenic paclitaxel- and doxorubicin-resistant breast tumor cell lines reveals distinct drug-specific genetic signatures of resistance. Breast Cancer Res Treat 2006, 96(1):17-39.

9. Hartz AM, Bauer B, Fricker G, Miller DS: Rapid modulation of P-glycoproteinmediated transport at the blood-brain barrier by tumor necrosis factor-alpha and lipopolysaccharide. Mol Pharmacol 2006, 69(2):462-470.

10. Assef $Y$, Rubio F, Colo G, del Monaco S, Costas MA, Kotsias BA: Imatinib resistance in multidrug-resistant $\mathrm{K} 562$ human leukemic cells. Leuk Res 2009, 33(5):710-716.

11. Kooij G, van Horssen J, de Lange ECM, Reijerkerk A, van der Pol SMA, van het Hof B, Drexhage J, Vennegoor A, Killestein J, Scheffer G, Oerlemans R, Scheper R, van der Valk P, Dijkstra CD, de Vries HE: T lymphocytes impair P-glycoprotein function during neuroinflammation. J Autoimmun 2010, 34(4):416-425
12. Chen $Y$, Nie D: Pregnane $X$ receptor and its potential role in drug resistance in cancer treatment. Recent Pat Anticancer Drug Discov 2009, 4(1):19-27.

13. Sinz M, Kim S, Zhu Z, Chen T, Anthony M, Dickinson K, Rodrigues AD: Evaluation of 170 xenobiotics as transactivators of human pregnane $\mathrm{X}$ receptor (hPXR) and correlation to known CYP3A4 drug interactions. Curr Drug Metab 2006, 7(4):375-388.

14. Tsan MF, Gao B: Endogenous ligands of Toll-like receptors. J Leukoc Biol 2004, 76(3):514-519.

15. Kawai T, Akira S: Signaling to NF-kappaB by Toll-like receptors. Trends Mol Med 2007, 13(11):460-469.

16. Ying W, Wang S, Shi J, Sun Y: ER-/ER+ breast cancer cell lines exhibited different resistance to paclitaxel through pulse selection. Med Oncol 2012, 29(2):495-502.

17. Mori N, Yamada Y, Ikeda S, Yamasaki Y, Tsukasaki K, Tanaka Y, Tomonaga M, Yamamoto N, Fujii M: Bay 11-7082 inhibits transcription factor NF-kappaB and induces apoptosis of HTLV---infected T-cell lines and primary adult T-cell leukemia cells. Blood 2002, 100(5):1828-1834.

18. Ma X, Cai Y, He D, Zou C, Zhang P, Lo CY, Xu Z, Chan FL, Yu S, Chen Y, Zhu $R$, Lei J, Jin J, Yao X: Transient receptor potential channel TRPC5 is essential for P-glycoprotein induction in drug-resistant cancer cells. Proc Natl Acad Sci U S A 2012, 109(40):16282-16287.

19. Bao L, Hazari S, Mehra S, Kaushal D, Moroz K, Dash S: Increased expression of P-glycoprotein and doxorubicin chemoresistance of metastatic breast cancer is regulated by miR-298. Am J Pathol 2012, 180(6):2490-2503.

20. Pascal LE, True LD, Campbell DS, Deutsch EW, Risk M, Coleman IM, Eichner L, Nelson PS, Liu AY: Correlation of mRNA and protein levels: cell type-specific gene expression of cluster designation antigens in the prostate. BMC Genomics 2008, 9:246.

21. Maguire O, Collins C, O'Loughlin K, Miecznikowski J, Minderman H: Quantifying nuclear p65 as a parameter for NF-kappaB activation: Correlation between ImageStream cytometry, microscopy, and Western blot. Cytometry A 2011, 79(6):461-469.

22. Alqawi $\mathrm{O}$, Bates $\mathrm{S}$, Georges E: Arginine482 to threonine mutation in the breast cancer resistance protein ABCG2 inhibits rhodamine 123 transport while increasing binding. Biochem J 2004, 382(Pt 2):711-716.

23. Rigalli JP, Ruiz ML, Perdomo VG, Villanueva SS, Mottino AD, Catania VA Pregnane $X$ receptor mediates the induction of $\mathrm{P}$-glycoprotein by spironolactone in HepG2 cells. Toxicology 2011, 285(1-2):18-24.

24. King CC, Sastri M, Chang P, Pennypacker J, Taylor SS: The rate of NF-kappaB nuclear translocation is regulated by PKA and $A$ kinase interacting protein 1. PLoS One 2011, 6(4):e18713.

25. Sun SC, Ganchi PA, Ballard DW, Greene WC: NF-kappa B controls expression of inhibitor I kappa B alpha: evidence for an inducible autoregulatory pathway. Science 1993, 259(5103):1912-1915.

26. Verstrepen L, Bekaert T, Chau TL, Tavernier J, Chariot A, Beyaert R: TLR-4, IL-1R and TNF-R signaling to NF-kappaB: variations on a common theme. Cell Mol Life Sci 2008, 65(19):2964-2978.

27. Kim KH, Jo MS, Suh DS, Yoon MS, Shin DH, Lee JH, Choi KU: Expression and significance of the TLR4/MyD88 signaling pathway in ovarian epithelial cancers. World J Surg Oncol 2012, 10:193.

28. Riad A, Bien S, Gratz M, Escher F, Westermann D, Heimesaat MM, Bereswill S, Krieg T, Felix SB, Schultheiss HP, Kroemer HK, Tschöpe C: Toll-like receptor4 deficiency attenuates doxorubicin-induced cardiomyopathy in mice. Eur J Heart Fail 2008, 10(3):233-243.

29. Kelly MG, Alvero AB, Chen R, Silasi DA, Abrahams VM, Chan S, Visintin I Rutherford T, Mor G: TLR-4 signaling promotes tumor growth and paclitaxel chemoresistance in ovarian cancer. Cancer Res 2006, 66(7):3859-3868.

30. Das KC, White CW: Activation of NF-kappaB by antineoplastic agents. J Biol Chem 1997, 272(23):14914-14920.

31. Roberts DJ, Goralski KB: A critical overview of the influence of inflammation and infection on P-glycoprotein expression and activity in the brain. Expert Opin Drug Metab Toxicol 2008, 4(10):1245-1264.

32. Miller DS, Bauer B, Hartz AM: Modulation of P-glycoprotein at the blood-brain barrier: opportunities to improve central nervous system pharmacotherapy. Pharmacol Rev 2008, 60(2):196-209.

33. Choi HJ, Kim J, Do KH, Park SH, Moon Y: Prolonged NF-kappaB Activation by Macrophage Inhibitory Cytokine 1-linked Signal in Enteropathogenic Escherichia coli-infected Epithelial Cells. Infect Immun 2013, 81(6):1860-9.

34. Bierhaus A, Schiekofer S, Schwaninger M, Andrassy M, Humpert PM, Chen J, Hong M, Luther T, Henle T, Kloting I, Morcos M, Hofmann M, Tritschler H, 
Weigle B, Kasper M, Smith M, Perry G, Schmidt AM, Stern DM, Häring HU, Schleicher E, Nawroth PP: Diabetes-associated sustained activation of the transcription factor nuclear factor-kappaB. Diabetes 2001, 50(12):2792-2808.

35. Harmsen S, Meijerman I, Febus CL, Maas-Bakker RF, Beijnen JH, Schellens JHM: PXR-mediated induction of P-glycoprotein by anticancer drugs in a human colon adenocarcinoma-derived cell line. Cancer Chemother Pharmacol 2009, 66(4):765-771.

36. Harmsen S, Meijerman I, Beijnen JH, Schellens JH: Nuclear receptor mediated induction of cytochrome P450 3A4 by anticancer drugs: a key role for the pregnane X receptor. Cancer Chemother Pharmacol 2009, 64(1):35-43.

37. Ma $Y$, Liu D: Activation of pregnane $X$ receptor by pregnenolone 16 alpha-carbonitrile prevents high-fat diet-induced obesity in AKR/J mice. PLoS One 2012, 7(6):e38734.

38. Zhou C, King N, Chen KY, Breslow JL: Activation of PXR induces hypercholesterolemia in wild-type and accelerates atherosclerosis in apoE deficient mice. J Lipid Res 2009, 50(10):2004-2013.

39. Ho WC, Dickson KM, Barker PA: Nuclear factor-kappaB induced by doxorubicin is deficient in phosphorylation and acetylation and represses nuclear factor-kappaB-dependent transcription in cancer cells. Cancer Res 2005, 65(10):4273-4281.

40. Kanagasabai R, Krishnamurthy K, Druhan $\sqcup$, llangovan G: Forced expression of Hsp27 reverses P-glycoprotein (ABCB1) mediated drug efflux and MDR1 gene expression in adriamycin resistant human breast cancer cells. J Biol Chem 2011, 286(38):33289-300.

41. Wahli W: A gut feeling of the PXR, PPAR and NF-kappaB connection. J Intern Med 2008, 263(6):613-619.

42. Gu X, Ke S, Liu D, Sheng T, Thomas PE, Rabson AB, Gallo MA, Xie W, Tian Y: Role of NF-kappaB in regulation of PXR-mediated gene expression: a mechanism for the suppression of cytochrome P-450 3A4 by proinflammatory agents. J Biol Chem 2006, 281(26):17882-17889.

43. Mencarelli A, Renga B, Palladino G, Claudio D, Ricci P, Distrutti E, Barbanti M, Baldelli F, Fiorucci S: Inhibition of NF-kappaB by a PXR-dependent pathway mediates counter-regulatory activities of rifaximin on innate immunity in intestinal epithelial cells. Eur J Pharmacol 2011, 668(1-2):317-324.

44. Sui H, Fan ZZ, Li Q: Signal transduction pathways and transcriptional mechanisms of $A B C B 1 / P g p$-mediated multiple drug resistance in human cancer cells. J Int Med Res 2012, 40(2):426-435.

doi:10.1186/s12935-014-0142-4

Cite this article as: Xu et al:: Differential drug resistance acquisition to doxorubicin and paclitaxel in breast cancer cells. Cancer Cell International 2014 14:142.

\section{Submit your next manuscript to BioMed Central and take full advantage of:}

- Convenient online submission

- Thorough peer review

- No space constraints or color figure charges

- Immediate publication on acceptance

- Inclusion in PubMed, CAS, Scopus and Google Scholar

- Research which is freely available for redistribution 